\title{
Realidad de las cooperativas de viviendas en la Comunidad Autónoma del País Vasco*
}

\author{
Reality of housing cooperatives in \\ the Autonomous Community of the Basque Country \\ Santiago Merino Hernández \\ Letrado del Consejo Superior de Cooperativas de Euskadi
}

DOI: $10.1387 /$ reves.20525

Sumario: 1. Introducción.-2. Antecedentes históricos. 2.1. Las cooperativas de viviendas en España. 2.2. Las cooperativas de viviendas en el País Vasco.-3. La realidad del sector.-4. Las ventajas de un modelo en auge.- -5 . Una propuesta no exenta de dificultades. - 6. La llegada de los nuevos modelos.-7. Las tendencias de reforma de la Ley de Cooperativas.-8. Conclusiones.-9. Bibliografía sobre cooperativas de viviendas.

\begin{abstract}
Resumen:
El cooperativismo de vivienda está en un momento decisivo en la Comunidad Autónoma del País Vasco motivado, además de por su recuperación en términos cuantitativos una vez constatado el inicio de la recuperación económica y de la activación del mercado inmobiliario, por la definitiva apuesta de los poderes públicos en relación a los nuevos modelos como el de la cesión de uso, y por la reforma de la vigente ley de cooperativas que garantice su eficacia desde los valores esenciales del cooperativismo como son la democracia y la participación.

Pretende este artículo analizar el estado de situación actual del cooperativismo de vivienda en el País Vasco desde sus antecedentes históricos hasta la actual reforma de su marco legal.
\end{abstract}

\section{Palabras claves:}

Cooperativas de viviendas, derecho a la vivienda, vivienda protegida, cesión de uso.

* Artículo que tiene su origen en la intervención que bajo el mismo título se desarrolló en la jornada "Economia Social y Cooperativas de Vivienda", organizada en Donostia por el Instituto de Derecho Cooperativo y Economía Social —GEZKI - de la Universidad del País Vasco/Euskal Herriko Unibertsitatea el 22 de junio de 2018. 


\begin{abstract}
:
The cooperative housing movement is experiencing a landmark moment in the Autonomous Community of the Basque Country, a situation prompted not only by its resurgence in quantitative terms following the confirmation of the beginnings of the economic recovery and the mobilisation of the housing market, but also by the strong level of backing by public authorities with regard to new models such as collective ownership, in addition to the overhaul of the current cooperatives law which guarantees success based on essential values of the cooperative moment such as democracy and participation.

This article seeks to analyse the current situation of the housing cooperative moment in the Basque Country, from its historical origins up to the current review of its legal framework.
\end{abstract}

\title{
Keywords:
}

Housing cooperatives, right to housing, protected housing, collective ownership.

\section{Introducción}

Desde los albores del siglo xx, el cooperativismo vasco ha conseguido gran arraigo en nuestro país, significándose especialmente por la fórmula del trabajo asociado y por su gran implantación y desarrollo en el sector industrial, dando lugar a la llamada "Experiencia Mondragón», que se ha convertido en un ejemplo de ámbito global.

La experiencia cooperativa en la Comunidad Autónoma del País Vasco (en adelante CAPV) ha alcanzado una madurez empresarial que se traduce en un importante impacto directo en la economía vasca. La implicación de las sociedades cooperativas en el desarrollo local del territorio donde se ubican y su contribución a un reparto más equitativo de la riqueza generada, fomentan una sociedad más solidaria, equilibrada y con mejores estándares de calidad de vida.

Atendiendo a todo ello, es indudable e innegable el hecho de la consolidación del cooperativismo y del denominado «Movimiento Cooperativo Vasco", que viene a englobar a todas las cooperativas con independencia de la clase a la que pertenezcan.

Así, las mencionadas sociedades han venido agrupándose y asociándose libre y voluntariamente mediante la constitución de federaciones sectoriales ${ }^{1}$, atendiendo como hecho diferencial a la clase de cooperativa

1 Arts. del 143 y 144 de la Ley de Cooperativas de Euskadi (en adelante LCE). 
a la que pertenecen en virtud de cuanto regula a los efectos la legislación, hasta la confluencia de todas ellas en la Confederación de Cooperativas de Euskadi²; máxima entidad asociativa representativa del cooperativismo vasco en el que se encuentran representadas todas las federaciones sectoriales existentes.

Estas federaciones sectoriales agrupan a las cooperativas tanto de trabajo asociado, como de enseńanza, consumo, crédito, agrarias, y transportistas, pero sin embargo nunca se había logrado hasta la fecha la creación de una federación de cooperativas de viviendas. Y ello probablemente porque, entre otros motivos, el cooperativismo de vivienda, en los términos en los que en la práctica se ha venido desarrollando en el País Vasco, es tendente a su no permanencia en el tiempo, es decir, a su disolución y definitiva liquidación una vez ha cumplido su objeto social; a la no existencia históricamente de una entidad "tractora» que liderara ese movimiento asociativo; y, por último, que los agentes directamente vinculados al sector de actividad parecían no ver la necesidad o al menos la ventaja de un asociacionismo para la defensa y promoción de los intereses de esta clase de cooperativas.

Sin embargo, fruto seguro de alguno de los acontecimientos acaecidos en el entorno de estas cooperativas durante los últimos años y su difusión en los medios de comunicación, se ha venido realizando una reflexión profunda sobre la materia, tanto desde el propio «Movimiento Cooperativo Vasco» como desde los poderes públicos. Como consecuencia de todo ello se ha constituido por una parte la Federación de Cooperativas de Viviendas-BIZIKOOP ${ }^{3}$; $y$, por otra, esta clase de cooperativas están teniendo una profunda revisión normativa en el marco del proyecto de reforma de la $\mathrm{LCE}^{4}$.

De esta forma pretendemos presentar la realidad de las cooperativas de viviendas en la Comunidad Autónoma del País Vasco (en adelante CAPV) en el momento actual, el estado de situación de la reforma legislativa, así como, en base a todo ello, visualizar su futuro más inmediato.

2 Vid. https://www.konfekoop.coop

${ }^{3}$ La Federación de Cooperativas de Viviendas - BIZIKOOP - ha sido constituida con fecha 17 de febrero de 2017 y registrada por el Registro de Cooperativas de Euskadi el 22 de marzo del mismo año (número de inscripción 2017.0.001.F).

${ }^{4}$ El Gobierno Vasco aprobó el 24 de mayo de 2016 el Proyecto de modificación de la LCE, estando en la actualidad en revisión dicho Proyecto a través de un nuevo borrador de Anteproyecto de Ley. 


\section{Antecedentes históricos}

\subsection{Las cooperativas de viviendas en España}

La existencia y desarrollo de las cooperativas de viviendas los podemos encontrar en las diferentes leyes de regulación de la vivienda en España desde principios del siglo xx. Sin embargo, fue a partir de los años 60 cuando apreciamos su primer desarrollo más significativo y prácticamente siempre vinculado a la vivienda protegida. Pero a nadie se le escapa que fue a partir de los años 80 cuando se fijan gran parte de debates, tanto jurídicos como económicos, sobre este modelo en los términos en los que hoy también nos los planteamos; sobre todo a raíz de la apuesta realizado desde las políticas de vivienda de gobiernos municipales y autonómicos que apoyaron explícitamente este modelo. Estos poderes públicos vieron en las cooperativas de viviendas un instrumento eficaz para resolver la problemática de la vivienda, muy especialmente la escalada en los precios que se estaba produciendo por la crisis económica.

La evolución y el desarrollo de las cooperativas de viviendas en España ha estado vinculada, fundamentalmente, a la legislación protectora de la vivienda, debido a que han actuado principalmente en la construcción de viviendas protegidas en sus diferentes épocas y bajo distintas denominaciones (casas baratas y económicas, de renta limitada, sociales, de protección oficial, etc.).

Como ya hemos adelantado, a pesar de que a finales del siglo xIX ya se dan las primeras experiencias de cooperativas de viviendas, vinculadas en su mayoría a cooperativas de consumo, puede afirmarse que realmente es en la década de los ańos 20 cuando se inician y desarrollan las primeras cooperativas de viviendas en el España. Este inicio y desarrollo es incentivado por las Leyes de Casas Baratas y Económicas, a través de las cuales se propició la edificación de barrios enteros de viviendas en las afueras de los núcleos urbanos consolidados 5 .

${ }^{5}$ Los antecedentes de la Ley de Casas Baratas y de la intervención del Estado en materia de vivienda se remontan a la Real Orden de 9 de septiembre de 1853, que ordenaba que se construyesen en Madrid y Barcelona "casas para pobres» y se tasaran los alquileres, aunque el primer gran paso lo daría la creación en 1883 de la Comisión de Reformas Sociales, que, transformada en 1903 en el Instituto de Reformas Sociales, efectuó en 1906 la primera propuesta para otorgar subvenciones y exenciones fiscales a las sociedades constructoras de alojamientos urbanos "populares». La piedra angular de la legislación sobre las Casas Baratas se puso en 1907 con la Preparación de las bases para un Proyecto de Ley de Casas Baratas, aprobándose el 12 de junio de 1911. Esta ley, juntos con sus modificaciones de 1914, 1916, 1921 (la más ambiciosa) y 1924, pretendían proveer de vivienda a los colectivos más desfavorecidos, siendo el antecedente de lo que luego entenderíamos por viviendas de protección oficial. 
La primera cita expresa a las cooperativas de viviendas se produce en la Ley de 9 de septiembre de 1931 cuando en su artículo 18.5 las considera como cooperativa de consumidores. Será el artículo 87 del Reglamento de Desarrollo de esta Ley el que plasme un artículo diferenciado estableciendo unos limites en el número de socios y la necesidad de autorización administrativa para las operaciones con terceros.

Tendremos que esperar a la Ley de Cooperación de 2 de enero de 1942, puesto que la Ley de Cooperativas de 27 de octubre de 1938 vuelve a reconducirlas a las de consumo, para encontrarnos a las cooperativas de viviendas como tipo específico diferenciado.

Frente a un reglamento de desarrollo de 11 de noviembre de 1943 que no aporta nada en la cuestión que nos ocupa, será el Reglamento de 13 de agosto de 1971 el que realice ya una regulación más pormenorizada de esta clase de cooperativas.

Hasta entonces, no podemos obviar la importancia de la Ley de 15 de julio de 1954 sobre viviendas de renta limitada que ampara la construcción de viviendas en régimen de propiedad por parte de distintos promotores, entre los que se encuentran las cooperativas de viviendas. Esta Ley y las disposiciones que la desarrollaron fueron fundamentales en la creación, desarrollo y expansión de las cooperativas de viviendas en España. Así, en esta época se construyeron un gran número de viviendas en régimen cooperativo mediante empresas, sindicatos, asociaciones populares, etc.

Las diferentes normas publicadas en la década de los años 60, sobre todo los Decretos de 24 de julio de 1963 (aprobación del texto refundido de la legislación sobre viviendas de protección oficial) y el Decreto de 24 de julio de 1968 (Reglamento para la aplicación de la Ley de viviendas de protección oficial), continúan la senda marcada por las leyes precedentes. Con estas normas, entrábamos, sin duda, en el inicio del desarrollo de la vivienda protegida en España bajo la fórmula, entre otras, cooperativa.

$\mathrm{Si}$ atendemos al asociacionismo de esta clase de cooperativas, diremos que desde 1958 y ante el crecimiento generalizado ${ }^{6}$, en algunas provincias se empezaron a agrupar con la intención de constituir organizaciones federadas del sector, denominadas entonces Uniones Territoriales. Las dos primeras iniciativas surgieron en Valencia y Madrid, provincias donde el número de cooperativas eran más numerosas. Como consecuencia de ello, en 1961 se aprobaron oficialmente las Uniones Territoriales de Valencia y

${ }^{6}$ Podemos destacar la fuerte implantación de este modelo promocional, entre otros lugares, en Madrid, Barcelona, Valencia, Alicante, Zaragoza, Albacete, Las Palmas, Tenerife, Navarra y Murcia. 
Madrid, naciendo lo que se entenderá como el movimiento cooperativo de viviendas en España ${ }^{7}$.

La Ley General de Cooperativas de 19 de diciembre de 1974 mantuvo las notas habidas hasta la fecha, y no fue hasta el Reglamento de 16 de noviembre de 1978 cuando nos encontramos con una regulación mas pormenorizada, así como particulares medidas de fomento.

Como también hemos adelantado, este cooperativismo presenta un nuevo impulso a principios de los años 80 , sobre todo a partir del último Reglamento citado, para dar respuesta a la demanda creada por el proceso económico en el ámbito del sector inmobiliario. Y es ahí, y hasta nuestros días, en donde podemos encontrar tanto la consolidación definitiva del cooperativismo de vivienda en los términos con el que hoy nos encontramos; cooperativismo que, por tanto, atesora una larga historia de aciertos $y$, por qué no decirlo, también algunos sonados fracasos ${ }^{8}$.

A finales de la década de los 80 entra en vigor en España la Ley General de Cooperativas de 2 de abril de 1987, que fue posteriormente derogada por la actual Ley de Cooperativas de 16 de julio de 1999, actualmente en vigor, que regula las cooperativas de viviendas en la sección 3 . $^{\mathrm{a}}$ del Capítulo X del Título I?

\footnotetext{
7 Actualmente el movimiento cooperativo de viviendas en Espańa cuenta con una Confederación (CONCOVI) que agrupa a las diferentes federaciones y uniones de cooperativas de viviendas que existen. Forman parte CONCOVI las siguientes organizaciones: Federación de Cooperativas de Viviendas y Rehabilitación de la Comunidad de Madrid, Federación de Cooperativas de Viviendas y Rehabilitación de la Comunidad de Valencia, Federación de Cooperatives D’Habitatges de Catalunya, Federación Aragonesa de Cooperativas de Viviendas, Unión de Cooperativas de Viviendas de Galicia, Federación de Cooperativas de Viviendas de Castilla y León, Unión de Cooperativas de Viviendas de Andalucía, Unión Sectorial de Cooperativas de Viviendas de Alicante y la Federación de Cooperativas de Viviendas de Canarias. Por último, hay que señalar que la Federación de Cooperativas de Viviendas — BIZIKOOP—, que desarrolla su labor en el ámbito vasco, se ha incorporado recientemente a CONCOVI. Vid, en este sentido, www.concovi.es.

${ }^{8}$ Recordemos a modo de ejemplo la suspensión de pagos de la cooperativa PSV y su gestora IGS en diciembre de 1993 con un pasivo de 200.000 millones de pesetas; los escándalos de Madrid —El Balcón de la Sierra, OFIGEVI...-, los problemas habidos en Vitoria-Gasteiz vinculados sobre todo al cooperativismo de viviendas protegidas (vid. http://cooperativistas afectados.blogspot.com), etc.

9 Sobre las cooperativas de viviendas en España, vid, por todos, LAMBEA, A., Cooperativas de viviendas (3. a edición), Comares, Granada, 2012; y MERINO, S., Cooperativas de viviendas, Tratado de Derecho de Cooperativas (Director Juan Ignacio Peinado), Tomo II (págs. 13931421), Tirant lo Blanc, Valencia, 2013; y en relación a los perfiles tributarios del uso de la vivienda en la economia social y colaborativa (monográfico), AA.VV. Revista Juridica de Economia Social y Cooperativa n. ${ }^{\circ}$ 31, Ciriec-España, Valencia, 2017.
} 
Motivado en gran parte por los fracasos, se observó un cierto declive de este sector durante los últimos ańos del s. $\mathrm{xx}$ y primeros del $\mathrm{xxI}$, sin olvidar como motivo la escasez de oferta de suelo protegido, el aumento de los costes de producción y por, en general, la crisis económica. Sin embargo, es ahora, con el comienzo de la salida de la crisis económica y con la llegada de los nuevos modelos de cooperativismo de vivienda cuando estamos observando un nuevo resurgir de este modelo.

\subsection{Las cooperativas de viviendas en el País Vasco}

En relación a las cooperativas de viviendas en la CAPV podemos decir que han seguido parámetros muy similares a los desarrollados en Espańa, si bien, y en un esfuerzo de sistematización, podríamos diferenciar cuatro momentos históricos en el ámbito geográfico en el que se incardina el presente artículo:

1. Cooperativas de viviendas constituidas a principios del siglo $\mathrm{xx}$, bajo la legislación de casas baratas y ubicadas fundamentalmente en Bizkaia. La característica de estas cooperativas eran su definición en términos de ayuda mutua propios de las corrientes ideológicas nacidas a mediados del siglo anterior en Inglaterra: cooperativismo, mutualismo, sindicalismo, etc.

2. Cooperativas de viviendas constituidas en todo el territorio bajo el proteccionismo franquista, fundamentalmente bajo el amparo de la Ley sobre viviendas de renta limitada y las disposiciones que la desarrollaron, a partir de la década de los años 60 del siglo xx hasta el final de la dictadura. Podemos encontrarnos todavía hoy alguna de estas cooperativas disueltas ex lege pero no definitivamente liquidadas entre otros motivos por la existencia de bienes todavía a su nombre ${ }^{10}$.

3. Cooperativas de viviendas constituidas a partir de los años $80 \mathrm{y}$ hasta la reciente crisis económica, destacando fundamentalmente las promociones desarrollados en Vitoria-Gasteiz ${ }^{11}$ y en varias comarcas guipuzcoanas (Bajo Deba, Goierri, etc.) y que se ha carac-

10 En este sentido vid. el punto 3 de la Disposición Transitoria Tercera de la LCE que establecía un plazo para la adaptación de los estatutos, quedando disueltas de pleno derecho y entrando en periodo de liquidación en el supuesto de no hacerlo.

${ }^{11}$ Cabe destaca la labor de promoción realizada por la Cooperativa Vitoriana de la Vivienda (COVIVI), fundada el 5 de noviembre de 1966, durante estos ańos no sólo en VitoriaGasteiz sino en todo Álava. 
terizado fundamentalmente por un cooperativismo de acceso a la propiedad y de vivienda protegida.

4. Cooperativas de viviendas en la actualidad que, como ocurre en Espańa, vuelven a desplegar su potencialidad por la apuesta de las entidades financieras, en ocasiones imposición de éstas, que tan sólo financian promociones bajo régimen cooperativo; la reflexión habida desde los poderes públicos que hace pensar en un nuevo y decidido apoyo; la llegada, también a nuestro país, de un nuevo cooperativismo de vivienda, de cesión de uso; así como la progresiva generalización del modelo de acceso a la propiedad a través de pequeñas promociones.

\section{La realidad del sector}

Adentrándonos en el ser de estas cooperativas, diremos en términos generales que son aquellas sociedades constituidas por personas físicas necesitadas de alojamiento, que se asocian para, bajo su propia organización, poder acceder a lo que será su propia vivienda.

Mediante la construcción de viviendas en régimen cooperativo desaparece la figura del promotor (o mejor dicho se hace coincidir con la del socio adjudicatario). El futuro adjudicatario de la vivienda, convertido en socio cooperativista, se ahorra el beneficio empresarial del promotor inmobiliario, por incorporarse a una sociedad, la cooperativa, que carece de ánimo de lucro. De esta forma, las cooperativas de vivienda han sido un instrumento de la economía social, que aplicado al volátil mercado inmobiliario, ha permitido el desarrollo de un sistema que persigue la adquisición de una vivienda por un precio idéntico a su coste, y en la que se adoptan las decisiones oportunas mediante los acuerdos de sus órganos sociales, en los cuales participan los socios promotores de forma democrática.

Atendiendo a la competencia exclusiva en materia cooperativa que ostenta la Comunidad Autónoma del País Vasco en virtud de la Ley Orgánica de 18 de diciembre de 1979, sobre el Estatuto de Autonomía del País Vasco, y más concretamente de su artículo 10.23; el artículo 1 de la LCE define a la sociedad cooperativa como «aquella sociedad que desarrolla una empresa que tiene por objeto prioritario la promoción de las actividades económicas y sociales de sus miembros y la satisfacción de sus necesidades con la participación activa de los mismos, observando los principios del cooperativismo y atendiendo a la comunidad de su entorno».

Esta definición no viene más que a recoger los históricos principios cooperativos consolidados a lo largo de la tradición legislativa en materia 
de sociedades cooperativas y que son las pautas mediante las cuales aquellas ponen en práctica sus valores.

Dicho esto, hemos de acudir a la especificidad relativa a la vivienda y así, actualmente las cooperativas de viviendas vienen reguladas por la LCE en los artículos 114 y 118, ambos inclusive, estableciéndose que el objetivo de estas sociedades es el «procurar para sus socios viviendas, servicios y edificaciones complementarias, pudiendo organizar el uso y disfrute de los elementos comunes y regular la administración, conservación y mejora de los mismos» ${ }^{12}$.

Como vemos, y ya hemos adelantado, el fundamento de las cooperativas no es otro más que el de sustituir la figura empresarial tradicional por una sociedad integrada por los destinatarios de su propia actividad. La mencionada sustitución responde a la finalidad de distribuir, entre los miembros del colectivo cooperativo, aquellos bienes necesarios o convenientes a más bajo costo (en este caso la vivienda), por entender que se ahorran los beneficios que en el sistema empresarial tradicional corresponderían al titular de la empresa.

En realidad, siempre nos hemos manifestado en el sentido de considerar a la sociedad cooperativa de viviendas como una clase específica de las cooperativas de consumidores, en la medida que los individuos son socios en tal condición, de destinatarios últimos de los bienes o servicios que éstas suministran ${ }^{13}$.

La legislación regula como posibilidades tanto la adjudicación de las mismas en régimen de propiedad, como en uso y disfrute, si bien como veremos más adelante hasta la fecha ha sido el régimen de propiedad el que ha acaparado el mercado, en contra de las experiencias más generalizadas más allá de nuestras fronteras.

Si analizamos los datos facilitados por el Registro de Cooperativas de Euskadi, competente en materia registral cooperativa en la CAPV, vemos que en los últimos años el número de las cooperativas de viviendas no ha dejado de crecer $^{14}$.

12 Sobre el Derecho de sociedades en relación a las cooperativas de viviendas, vid., por todos, MERINO, S., Cooperativas de viviendas, Manual de Derecho de Sociedades Cooperativas, Consejo Superior de Cooperativas de Euskadi, Vitoria-Gasteiz, 2008, págs. 337-354.

13 Fernando Elena considera a las cooperativas de viviendas como cooperativas de consumo especializadas: "La cooperativa de viviendas es una cooperativa de consumidores especializada en el suministro a sus socios de un lugar donde vivir en unión de sus familias (...). Son empresas inmobiliarias propiedad de los usuarios de las viviendas. Vid, ELENA, F., Las tendencias actuales del cooperativismo de viviendas, Jornadas de estudio sobre cooperativismo, Dirección General de Cooperativas y Empresas Comunitarias, Ministerio de Trabajo, Madrid 1978, pág. 203.

${ }_{14}$ No podemos negar que muchas de estas cooperativas ya no realizan su actividad y sin embargo no han sido liquidadas, pero con los datos queremos reflejar el notable y progresivo interés que han ido generando en los diferentes operadores en el mercado inmobiliario, usuarios y sociedad en general. 


\section{Evolución de las cooperativas de viviendas en la CAPV}

\begin{tabular}{|c|c|c|c|}
\hline Año & Coops. & Año & Coops. \\
\hline 2010 & 270 & 2002 & 123 \\
\hline 2011 & 288 & 2003 & 144 \\
\hline 2012 & 316 & 2004 & 188 \\
\hline 2013 & 322 & 2005 & 211 \\
\hline 2014 & 350 & 2006 & 228 \\
\hline 2015 & 376 & 2007 & 233 \\
\hline 2016 & 396 & 2008 & 236 \\
\hline 2017 & 421 & 2009 & 251 \\
\hline
\end{tabular}

Fuente: Registro de Cooperativas de Euskadi.

Continuando con el significado de nuestro cooperativismo de viviendas diremos que cuando una persona adquiere una vivienda en régimen cooperativo no la compra, sino que la construye y adquiere. En consecuencia, los socios, promotores de las viviendas, deben de sufragar, en su integridad, todos los costes derivados de la promoción: suelo, construcción, proyectos, licencias..., incluido si ésta es de protección pública.

Como vemos, si la actividad cooperativizada se caracteriza por la gestión de intereses, la cooperativa no vende las viviendas a sus socios, sino que las adjudica, compensando contablemente la citada adjudicación con las cantidades entregadas a cuenta, en lo que a todas luces podemos considerar como un negocio traslativo ${ }^{15}$.

Efectivamente, las cantidades aportadas por los socios cooperativistas son una derrama del coste de la construcción. De ahí que en el proceso cooperativo desaparezca el lucro en tanto que las aportaciones económicas de los socios terminan cuando se alcanza el costo real y efectivo. Así, en las cooperativas de viviendas, tal y como describíamos la actividad cooperativizada, debemos diferenciar las aportaciones a capital realizadas por los socios y fundamento de su participación societaria en cuanto recursos propios, de las cantidades entregadas a cuenta para adjudicación de vivienda.

Con todo, diremos que, si bien la cooperativa actúa en su propio nombre como consecuencia de su personalidad jurídica independiente, lo hace por cuenta del socio, es decir, la cooperativa recibe las cantidades entregadas a cuenta para adjudicación de vivienda no a título de propiedad, no

15 Vid. Sentencias del Tribunal Supremo de 2 de octubre de 1990, 4 de diciembre de 1990, 1 de octubre de 1991, 8 de mayo de 1993, 16 de junio de 1993, y 8 de noviembre de 1993. 
como parte de su patrimonio, sino por cuenta e interés del socio y sólo para su gestión. Estas cantidades son masas económicas independientes sujetas a un trato contable y fiscal diferenciado y cuyo objetivo es alcanzar un fin determinado.

Por otro lado, hemos de apuntar que tradicionalmente se ha venido reconociendo en el País Vasco la importancia del movimiento cooperativo, así como la necesidad del apoyo al mismo a través de medidas específicas de fomento; todo ello incardinado en el precepto constitucional (art. 129.2) por el que se establece que «los poderes públicos promoverán eficazmente las diversas formas de participación en la empresa y fomentarán, mediante una legislación adecuada, las sociedades cooperativas».

Todo esto ha adquirido especial trascendencia y tiene un reflejo específico, en el sector de actividad que tratamos, a través de medidas como la disposición prevista en el art. 138.7 de la LCE por la que se posibilita a las cooperativas de viviendas, para el cumplimiento de sus fines sociales, la adquisición de terrenos de gestión pública por el sistema de adjudicación directa, artículo que en gran parte ha sido el gran motor del desarrollo de este cooperativismo relacionado con la vivienda protegida ${ }^{16}$.

En similar sentido se pronunciaba el legislador vasco cuando en el artículo 17.b) de la Ley de 30 de junio de 2006, de Suelo y Urbanismo, establece que «... podrán enajenarse bienes directamente, sin necesidad de concurso, con los requisitos que en cada caso requiera la normativa:

b) Cuando los peticionarios sean entidades de carácter asistencial o social sin ánimo de lucro, tales como fundaciones, mutualidades, cooperativas y otras que promuevan la construcción de viviendas sometidas a algún régimen de protección pública."

Sin embargo, y también en esta ocasión por parte del legislador vasco, a través de la Ley de 18 de junio de 2015, de Vivienda, en su artículo 18.1.b) se ha establecido que "... podrán enajenarse directamente, sin necesidad de licitación pública, los bienes del Patrimonio Público de Suelo, con los requisitos

16 En relación a la vivienda protegida, vid. el Decreto de 4 de marzo de 2008 sobre el régimen jurídico de viviendas de protección pública y medidas financieras en materia de viviendas y suelo; y la Orden de 15 de octubre de 2012, del Consejero de Vivienda, Obras Públicas y Transportes, del registro de solicitantes de vivienda y de los procedimientos para la adjudicación de viviendas de protección oficial y alojamientos dotacionales de régimen autonómico. De especial relieve encontramos la letra b) del punto 2 del art. 25 de la Orden apuntada cuando excepciona, en relación a los procedimientos generales de adjudicación, los llevados a cabo por sociedades cooperativas, sin perjuicio de que los socios adjudicatarios cumplan con los requisitos de acceso previstos por la normativa vigente. 
$y$ condiciones que se determinen reglamentariamente, cuando concurra alguna de las siguientes circunstancias:

b) Cuando el adquirente sea una entidad sin ánimo de lucro, declarada de utilidad pública, que promueva la construcción de viviendas sometidas a algún régimen de protección pública.»

No cabe duda que esta regulación viene a complicar notablemente el fomento de las promociones cooperativas, en la medida que éstas disponen de un largo procedimiento administrativo para conseguir la declaración de utilidad pública ${ }^{17}$, y que en nada se ajusta a la realidad temporal en la gestión promocional cooperativa, más si cabe en proyectos caracterizados por su duración determinada y centrados en tan sólo una única promoción. Confiamos que la nueva Ley de Cooperativas que salga del actual proceso de reforma ponga fin a esta situación de evidente colisión de normas y barrera sin duda a la promoción de la vivienda protegida bajo parámetros cooperativos.

\section{Las ventajas de un modelo en auge}

Es amplio el consenso sobre las bondades del cooperativismo de vivienda, que a todas luces presenta ventajas de orden económico, financiero y social, frente a otros modelos de promoción. Un cooperativismo que aporta ventajas económicas en la medida que regula los precios y más en concreto ayuda a equilibrar o a minorar el desajuste entre la oferta y la demanda de viviendas en el ámbito geográfico en el que actúa.

La cooperativa de viviendas, evitando intermediarios, busca la adjudicación a precio de coste por lo que técnicamente carecen de ánimo de lucro, si bien una vez cubiertas las necesidades de la misma podrá enajenar o arrendar a terceros las instalaciones y edificaciones complementarias de su propiedad al objeto, por ejemplo, de cubrir los gastos de mantenimiento una vez ya adjudicados a sus socios las viviendas y/o locales. Así mismo, cabe recordar cómo en el caso de observarse plusvalías en la enajenación de locales o garajes éstas son destinadas a la minoración del coste de las viviendas y anejos, en su caso, vinculados.

Una de las ventajas que hemos de poner igualmente de relieve es todo aquello que se deriva de su organización democrática y solidaria. Hablamos de una entidad en la que los socios eligen democráticamente a sus órganos

17 Decreto de 2 de febrero de 1999 por el que se aprueba el Reglamento sobre procedimientos y requisitos relativos a las sociedades cooperativas de utilidad pública. 
representativos, y por tanto éstos en todo momento disponen del control y la gestión de la sociedad, siempre en una actuación que debe incardinarse en los Principios Cooperativos de la $\mathrm{ACI}^{18}$.

Además de por el control de los órganos sociales por parte de los socios, si por algo se caracteriza el modelo es por el control económico de todas las operaciones económicas por parte de éstos, cuestión de singular importancia precisamente en las cooperativas de viviendas por el volumen que alcanzan las mismas. Así, antes de presentar sus cuentas anuales a la Asamblea General ordinaria para su estudio y aprobación, ha de someterlas a una auditoría de cuentas (y letrado asesor, en su caso), en el cumplimiento de la legislación vigente ${ }^{19}$, viniendo a garantizar el correcto devenir de la promoción. Asimismo, en este contexto de fiscalización, la Asamblea General podrá nombrar una Comisión de Vigilancia ${ }^{20}$ como máxima garantía de control y para no monopolizar el poder interno en la misma. En esta Comisión, si los estatutos así lo plasman, podrán participar terceros no socios que reúnan los requisitos de honorabilidad, cualificación profesional y experiencia técnica o empresarial adecuados en relación con las funciones del órgano.

Continuando con las ventajas, hemos de recordar que la cooperativa de viviendas es una sociedad fiscalmente protegida (en concreto especialmente protegida). Esta calificación conlleva un especial beneficio tributario que opera sin ningún tipo de declaración administrativa previa y se concreta, entre otros, en los impuestos de sociedades, actividades económicas; y transmisiones y actos jurídicos documentados ${ }^{21}$.

18 Adhesión voluntaria y abierta: libertad de entrada y salida de la sociedad; Participación económica de los socios: la cooperativa de viviendas en la búsqueda de la reducción de los costes fomenta la financiación directa con capitales provenientes de las aportaciones de los socios; Autonomía e independencia: la cooperativa de viviendas tiene personalidad jurídica propia y se mantiene ajena a cualquier interés, influencia o condicionante tanto de entidades públicas como privadas; Educación, formación e información: todos los socios a través del equipo técnico conocen en todo momento el ritmo de la construcción y cuantas cuestiones se deriven de la promoción, estando en todo momento las cuentas a disposición de los cooperativistas en la sede social; Cooperación entre cooperativas: la cooperativa de viviendas en todo caso dispone del seguro apoyo del ya consolidado movimiento cooperativo vasco; Interés por la comunidad: la actividad de las cooperativas de viviendas revierten en el beneficio de la sociedad gracias a la obtención de costes reducidos, la regulación de precios, la composición demográfica y la reactivación de la economía, al tiempo que canaliza una demanda retenida por motivos económicos en nuestra ciudad y posibilita el acceso finalmente y de forma digna a una vivienda a un precio razonable. Sobre los principios cooperativos y su realidad empresarial vid. https://ica.coop/es

19 Vid. artículo 117 de la LCE.

20 Vid. artículo 50 de la LCE.

21 Vid, en esta ocasión las tres normas aprobada en los Territorios Históricos. A saber: Norma Foral de 22 de mayo de 1997 del Territorio Histórico de Gipuzkoa, sobre Régimen Fiscal de las Cooperativas; Norma Foral de 9 de junio de 1997 del Territorio Histórico de Álava, 
Además, disfruta de particulares atenciones y ayudas específicas de los poderes públicos (fundamentalmente de la Dirección de Economía Social del Gobierno Vasco, del Consejo Superior de Cooperativas de Euskadi, así como del resto de Administraciones Públicas) manteniendo por lo general una estrecha colaboración con las entidades de crédito más significativas de su entorno. En este sentido, y en el marco del apoyo público, no podemos obviar la importancia de los instrumentos de resolución de conflictos, muy especialmente el arbitraje cooperativo, puestos a disposición de las cooperativas por BITARTU - Servicio Vasco de Arbitraje Cooperativo- (Consejo Superior de Cooperativas de Euskadi) ${ }^{22}$. Los procedimientos de arbitraje, mediación y conciliación, además de la resolución de todo tipo de dudas y atención de consultas tanto a los cooperativistas como a los operadores jurídicos que desarrollan su actividad en el ámbito de esta clase de cooperativas, ayudan sin duda a evitar costosos y largos procedimientos judiciales tan característicos de las promociones inmobiliarias.

Además, encontramos posibles ventajas de orden urbanístico en la medida que el modelo cooperativo en el sector de la vivienda posibilita núcleos integrados buscando de esta forma barrios compuestos no sólo de suma de individualidades sino de un hábitat realmente compartido; todo ello sin olvidar la posibilidad de organizar elementos comunes para un mejor aprovechamiento de los servicios.

En definitiva, el cooperativismo de vivienda se caracteriza sobre todo por la libertad de elección, siempre entendiendo ésta desde un punto de vista colectivo. Los socios deciden la forma y las características de las viviendas que van a construir, adecuándolas a sus necesidades personales (las viviendas que se adjudican) como a las necesidades de la colectividad en la búsqueda de un proyecto compartido.

\section{Una propuesta no exenta de dificultades}

Abordadas las ventajas de las cooperativas de viviendas, no podemos obviar que hemos presenciado dificultades en la propuesta, algunas de singular repercusión incluso mediática, que han provocado la aparición de sombras sobre el hecho cooperativo en este ámbito promocional, sobre todo en los últimos años.

sobre el Régimen Fiscal de las Cooperativas; y Norma Foral de 14 de octubre de 1997 del Territorio Histórico de Bizkaia, sobre Régimen Fiscal de las Cooperativas (artículos 10.bis en las dos primeras y 9 bis en la tercera, introducidos por Normas Forales de modificación de las primeras).

${ }^{22}$ https://www.csce-ekgk.coop/es/bitartu 


\section{a) Desconocimiento de los socios de su propia realidad jurídica}

En la práctica, y fundamentalmente en cuanto a aquellas cooperativas que tienen por objeto promocionar y procurar a sus socios viviendas protegidas, cabe destacar el desconocimiento, en gran parte generalizado, de los socios cooperativistas tanto del hecho cooperativo y de la fórmula del cooperativismo de vivienda, como del complejo negocio inmobiliario y de la implicación económica y jurídica que supone. Todo ello, en algunas ocasiones, ha dado lugar a graves problemas que han hecho peligrar incluso el resultado del proyecto.

Así, es habitual por parte de los socios adjudicatarios de las cooperativas de viviendas que promueven vivienda protegida la creencia de la no repercusión de los riesgos promocionales a pesar de su condición de socios adjudicatarios. Quizás otro elemento distorsionador de este aspecto sea el hecho de que al ser adjudicatarios de una vivienda protegida vienen obligados al cumplimiento de los requisitos establecidos por la Administración para serlo, y siendo ésta la responsable de la verificación de dicho cumplimiento a través del visado de los contratos de adjudicación correspondientes, se fortalece la convicción del socio de que se trata de una promoción pública y no privada bajo régimen cooperativo.

Por todo lo cual, pensamos es necesario prestar especial atención a la hora de aportar la debida información, por parte de los promotores del proyecto, a los socios en el momento de su incorporación a la cooperativa, remarcando de forma expresa la condición de promotores con la responsabilidad que de tal consideración se deriva ${ }^{23}$.

\section{b) Particular mención a las dificultades financieras}

Tras el estallido de la burbuja inmobiliaria, muchas de las promotoras, incluso constructoras, convencionales han visto negado el crédito por parte de entidades financieras y se han tenido que fijar en el hecho cooperativo en donde sí se conseguía, en principio, financiación. En efecto, es habitual que muchos proyectos acudan a esta fórmula tan sólo para garantizar el acceso al crédito promotor y no tanto por las bondades del sistema descritas, sobre todo, como decimos, si la iniciativa proviene de operadores jurídicos

23 De esta forma debe hacerse un esfuerzo a la hora de trasladar en el momento de la adquisición de la condición de socio los derechos y obligaciones que establece la LCE en los artículos 22 a 25; así como las particularidades que se derivan de los estatutos sociales y de los contratos de adquisición de las viviendas y/o locales. 
ajenos al modelo cooperativo y una vez que han encontrado barreras infranqueables de cara a la financiación de la promoción.

Por otro lado, lo que resulta evidente deducir es que es inviable la autofinanciación de la ejecución de la obra por parte de los propios socios adjudicatarios que la conforman. Más aún en el supuesto de las cooperativas de viviendas que promueven vivienda protegida, cuya normativa establece un límite de aportaciones a desembolsar por los adjudicatarios en concepto de cantidades entregadas a cuenta para adjudicación de vivienda de hasta el $20 \%$ del precio de la vivienda y el $40 \%$ de los anejos vinculados con carácter previo a la efectiva adjudicación a su favor de los mismos (vivienda y anejos) mediante escritura pública ${ }^{24}$.

Como consecuencia de lo expuesto, en la práctica las cooperativas tienden a negociar con las entidades financieras una línea de crédito hipotecario que les posibilite en primera instancia abordar la compra del solar donde se prevé desarrollar la promoción para, con posterioridad, tratar de convertir la citada línea de crédito en un crédito promotor que viabilice la consecución del proyecto promocional.

A la fecha, es habitual que las entidades financieras exijan a las cooperativas la acreditación de que la misma está conformada por tantos socios adjudicatarios como viviendas y anejos vinculados. Incluso empieza a ser también habitual que las entidades financieras requieran información (económica y laboral ${ }^{25}$ ) relativa a todos y cada uno de los socios adjudicatarios que forman parte de la cooperativa para tratar de medir y precisar el riesgo de eventuales dificultades de pago o insolvencias.

Por si lo ya expuesto no fuera suficiente, de unos años a esta parte, además se han empezado a solicitar a los socios por parte de las entidades financieras avales mancomunados hasta el límite del precio de la vivienda o local que cada uno vaya a adjudicarse.

Con todo ello, y como ya hemos señalado, las entidades financieras vienen condicionando en muchas ocasiones la concesión de líneas de crédito a todos los potenciales promotores al hecho de que desarrollen sus proyectos bajo régimen cooperativo, al entender que es la mejor manera posible de diversificar el riesgo del hecho promocional, en la medida que son los socios cooperativistas los promotores y, por tanto, quienes asumen en última instancia la responsabilidad del riesgo empresarial inherente al proyecto financiado.

24 Vid. en este sentido el ya citado Decreto de 24 de julio de 1968 por el que se aprueba el Reglamento de Viviendas de Protección Oficial.

25 De esta forma han reaccionado las entidades financieras ante el alarmante incremento del desempleo y precarización del empleo entre la población, con especial afección sobre la juventud. 


\section{c) Las sociedades gestoras de cooperativas y su relación con éstas}

Dada la complejidad que supone llevar a cabo una promoción de viviendas, es habitual que la cooperativa busque la ayuda de una serie de profesionales que le presten su asistencia a cambio de una contraprestación económica.

En este contexto resulta relevante el papel de las sociedades gestoras, además de por aportar la necesaria asistencia técnica (personal cualificado que elabora los proyectos técnicos, realización del seguimiento de la obra, control de su correcta ejecución, cumplimiento de los plazos y de las normas urbanísticas...), como empresas que son capaces de prestar los servicios profesionales que requiere la promoción cooperativa de manera integral y haciendo definitivamente viable esta forma de promoción.

Pero, es más, viene ya siendo habitual en la actualidad que las cooperativas de viviendas sean constituidas por las propias sociedades gestoras, frente a un pasado en el que mayoritariamente eran promovidas por el movimiento asociativo, entidades públicas o los propios socios ${ }^{26}$. Estas cooperativas que han nacido «sin socios» han dado lugar a un buen número de conflictos tanto en los Tribunales de Justicia como ante el Servicio Vasco de Arbitraje Cooperativo —BITARTU— ${ }^{27}$. En este sentido, han sido muchas las críticas vertidas sobre las falsas cooperativa por parte de la doctrina más reciente al tiempo que reclaman una mayor intervención desde los poderes públicos en fórmulas que no hacen mas que desprestigiar a todo el cooperativismo de viviendas. Así, como consecuencia de sonoros y mediáticos fracasos se ha extendido en algunos ámbitos de nuestro entorno la idea de que todo el modelo cooperativo, por lo menos gran parte del mismo, está en manos de sociedades con ánimo de lucro que no hacen más que utilizar la fórmula cooperativo en un generado fraude de ley y sobre todo muy alejado de los principios cooperativos que se presupone a este tipo societario.

No podemos compartir este posicionamiento en la media que se hace de lo excepcional el hilo conductor de ese discurso, obviando todo un cooperativismo de viviendas impulsado y controlado desde el ámbito del propio Gobierno Vasco, así como las innumerables promociones de base municipal que se han desarrollado en la $\mathrm{CAPV}^{28}$, las importantes promociones

${ }^{26}$ La mayoría de cooperativas de viviendas tienen contratados los servicios de alguna sociedad gestora. Esta asistencia en casi todos los supuestos es integral, es decir, abarcando la totalidad de las necesidades de gestión de la cooperativa.

27 Vid. https://www.csce-ekgk.coop/es/bitartu/laudos-arbitrales

${ }_{28}$ No obstante, y a pesar de defender la promoción realizada desde el ámbito municipal, se ha echado en falta en ocasiones en los pliegos administrativos de los convenios para la adjudicación de terrenos de titularidad pública por el sistema de adjudicación directa o a través de 
habidas (y que van a continuar) gestionadas por sociedades de prestigio avaladas incluso por los poderes públicos, pequeños proyectos caracterizados por la estrecha relación cooperativa-gestora, y un largo etc., que nos hacen defender la promoción cooperativa como uno de los modelos más adecuados para la adquisición de una vivienda y/o local dentro de un complicado negocio como es el de la promoción inmobiliaria.

Además, el legislador español ha ido reaccionado y acotando la responsabilidad de quienes son efectivamente promotores reales y que utilizan la fórmula cooperativa para orillar dicha responsabilidad. Así, debemos citar el artículo 17.4 de la Ley de 5 de noviembre de 1999 de Ordenación de la Edificación cuando señala que «la responsabilidad del promotor que se establece en esta Ley se extenderá a las personas físicas o jurídicas que, a tenor del contrato o de su intervención decisoria en la promoción, actúen como tales promotores bajo la forma de promotor o gestor de cooperativas o de comunidades de propietarios u otras figuras análogas", significando un auténtico levantamiento de velo en la determinación de la responsabilidad real en relación a proyectos que pudieran resultar fraudulentos ${ }^{29}$.

De alguna forma pensamos, como ya señalaba Fernando Elena en 1978, que "probablemente las gestoras cumplen una función de promotoras, pero ello no puede considerarse algo negativo. (...) Creo que no cabe más que este sistema, siempre que los gestores actúen estrictamente en beneficio de quienes acaban pagándoles por su gestión. El hecho de quién ha tenido la iniciativa me parece menos importante siempre que al final haya una serie de viviendas cuya construcción haya sido administrada colectivamente y al precio más ajustado posible a la calidad conseguida» ${ }^{30}$. Si, como decimos, damos por buena esta reflexión, por lo menos en parte porque entendemos que la misma no podríamos desligarla de los principios cooperativos, se torna en prioritario contar con sociedades gestoras de prestigio, solvencia y profesionalidad que compartan en su quehacer diario los citados principios y que de esta forma se convierten en garantía para el éxito de cualquier promoción ${ }^{31}$. De

concursos públicos en la que participaran cooperativas, la exigencia de la acreditación de la experiencia y buen hacer de la sociedad gestora contratada por aquella para una gestión profesionalizada. En este sentido, ya nos hemos manifestado en varias ocasiones reclamando un registro de entidades gestoras de cooperativas de vivienda al estilo, por ejemplo, del registro de empresas contratistas, y en donde se establezcan los requisitos para que una sociedad gestora pueda contratar con una cooperativa para la promoción de viviendas protegidas.

29 En este sentido, y en nuestro entono más cercado, y en este caso calificando la conducta de la gestora como de autocontratación vid. las Sentencias de la Audiencia Provincial de Álava de 1 de diciembre de 2011 y de 31 de marzo de 2014.

30 ELENA, F., op. cit., pág. 203.

31 De hecho, siempre hemos entendido el contrato de la sociedad gestora como un arrendamiento de servicios gerenciales muy similar al que pudiera firmar un director en una coope- 
ahí que defendamos la existencia de una gestión profesional acreditada que preste los servicios que precisen las cooperativas en el conocimiento del sector, permitiendo, entre otras cuestiones, la naturaleza participativa de los socios y la toma democrática de las decisiones en la cooperativa.

Por último, y como garantía del sistema, debemos citar la capacidad interventora de la Administración Pública, en nuestro caso del Departamento de Trabajo y Justicia del Gobierno Vasco al que le corresponde la función inspectora en relación al cumplimiento de la LCE, también para cooperativas de viviendas y que podría conllevar, además de sanciones económicas, la intervención temporal de la cooperativa o, incluso, la descalificación de la misma ${ }^{32}$.

\section{La llegada de los nuevos modelos}

Como ya hemos apuntado anteriormente, en la actualidad las cooperativas que posibilitan la adquisición de una vivienda en régimen de propiedad son las que hasta la fecha han acaparado la realidad en el sector ${ }^{33}$.

Sin embargo, tanto los poderes públicos como desde el ámbito de la investigación ${ }^{34}$ se han fijado en los modelos implantados en el norte en Europa, así como en Alemania, Canadá y Uruguay con sus evidentes singularidades, en donde están generalizadas las cooperativas de viviendas en cesión de uso ${ }^{35}$.

rativa por ejemplo de trabajo asociado, si bien en este último caso regido por el Real Decreto 1382/1985, de 1 de agosto, por el que se regula la relación laboral de carácter especial del personal de Alta Dirección.

32 Vid. artículos 139 a 142 de la LCE.

${ }^{33}$ Las razones que hacen que nuestro modelo cooperativo se base en la propiedad tradicional son básicamente la falta de regulación — desarrollo - hasta la fecha del contenido de la cesión de uso, así como la mentalidad española sobre la propiedad de la vivienda.

34 Así, es destacable el pionero grupo de investigación creado por las investigadoras Gala Cano y Aitziber Etxezarreta de las Universidades de Murcia y el País Vasco respectivamente, y Santiago Merino, letrado del Consejo Superior de Cooperativas de Euskadi; quienes desde hace varios ańos vienen estudiando ya estos modelos tanto en Espańa como en el ámbito internacional. En este marco, este grupo de investigación ha llevado la experiencia española al ámbito internacional. Vid. Etxezarreta, A., Merino, S., Cano, G., Dol, K., \& J. Hoekstra (forthcoming), "The emergence of housing cooperatives in Spain", in Van Bortel, G., Gruis, V., Nieuwenhuijzen, J. \& B. Pluijmers (eds), Affordable Housing. Governance and Finance, Routledge, Taylor and Francis.

35 Vid., por todos, ETXEZARRETA, A. y MERINO, S.: «Las cooperativas de vivienda como alternativa al problema de la vivienda en la actual crisis económica», Revista de Estudios Cooperativos, n. ${ }^{\circ} 113,2013$, págs. 108 y ss. 
En este modelo las viviendas quedan en propiedad de la cooperativa y en ella los socios disfrutan de un derecho de uso indefinido sobre las mismas con una renta a un precio reducido. De ese modo se explora una vía intermedia, más asequible económicamente que la propiedad y con menos incertidumbre que el alquiler. Una opción que, a pesar de los esfuerzos que se están haciendo desde diferentes ámbitos, no acaba de despegar en nuestro entorno.

Este modelo, que nació en Dinamarca allá por 1911, ha tenido una lenta pero progresiva implantación en los últimos años en España. El modelo «Andel» funciona de manera democrática, los socios nunca pueden transformarlo en una propiedad tradicional, teniendo más derechos que un inquilino convencional ya que es un modelo que establece el uso indefinido de la vivienda.

En este sentido, la promoción o adquisición de un conjunto de viviendas en inmueble único puede realizarse por una cooperativa que se constituya para tal fin. Para acceder a la condición de socio habrá de abonarse el importe económico que sea fijado por los órganos de gobierno de la misma en función de los costes de la promoción y mantenimiento del inmueble. Este importe de entrada se reembolsará en el caso de que quien lo hubiera abonado enajenara su derecho de uso a otra persona bajo la fiscalización de los responsables de la cooperativa que habrán de garantizar la inexistencia de lucro o beneficio especulativo en la mencionada operación. El derecho de uso que ostenta cada uno de los socios tiene carácter indefinido y puede ser también transmisible en caso de fallecimiento en sus propios términos y contenidos. En contraprestación al mismo, se abona un canon o renta social establecido por la cooperativa de acuerdo a los costes de promoción, construcción, amortización, mantenimiento, mejoras y conceptos asimilables correspondientes al inmueble residencial. Además, del particular y ventajoso régimen jurídico se abre todo un abanico de posibilidades en el compartir y en la generación de espacios comunes de cara a la integración de todas las personas en un único espacio: mismos intereses, atención sociosanitaria, gastos compartidos, comunicación intergeneracional..., en definitiva, ayuda mutua.

En España las leyes sobre cooperativas permiten hacer cooperativas de viviendas para la propiedad o para la administración de bienes, posibilitándose a nuestro entender la cesión de uso, aunque en la práctica, y como ya hemos apuntado, ésta ha sido absolutamente residual hasta la fecha ${ }^{36}$.

36 Siempre se menciona a TRABENCO, fundada en 1967 como ejemplo pionero de esta fórmula en España. En este proyecto se trataba de racionalizar el comportamiento de los «consumidores» de viviendas, haciéndoles arrendatarios en lugar de propietarios. Pero luchar contra la mentalidad generalizada a favor de la propiedad, y al tiempo, pedir unas aportaciones como 
Ha sido la Ley de 18 de junio de 2015 de Vivienda la que en su Disposición Adicional Tercera establecería por primera vez en una norma la posibilidad de este modelo, cuando regulaba la «Promoción o adquisición de conjuntos residenciales por asociaciones sin ánimo de lucro, en régimen de cesión de uso» ${ }^{37}$. Por último, el plan Director de Vivienda 2018-2020 ${ }^{38}$ en el quinto eje estratégico busca, entre otras cuestiones, promover la crea-

socio equivalentes a la entrada a pagar para adquirir un piso y, además, una vez habitando la vivienda, unos pagos mensuales (teóricamente rentas de alquiler) también tan altos como los de las hipotecas que las gravaban, hizo fracasar el proyecto en los términos en los que inicialmente estaba configurado. Posteriormente ya vendrían las experiencias en Catalunya (Cal Cases, La Borda, Sostre Civil, etc.) o Madrid (Entrepatios), si bien las experiencias más exitosas las hemos de encontrar en el sector «senior» con cooperativas ya asentadas como, por ejemplo, Trabensol (también en Madrid) u otros en ciernes como Brisas del Cantábrico (Cantabria). Sobre todo ello, vid por todos, ETXEZARRETA, A. \& CANO, G. \& MERINO, S., Las cooperativas de viviendas de cesión de uso: experiencias emergentes en España, Revista de Economía Pública, Social y Cooperativa, n. ${ }^{\circ}$ 92, Ciriec-España, Valencia, 2018, págs. 61-86.

37 Disposición Adicional Tercera:

1. Sin perjuicio de otras modalidades de autopromoción o de promoción a través de cooperativas $u$ otras formas de asociación con la finalidad de la adjudicación de viviendas y anejos a sus participes, la promoción o adquisición de un conjunto de viviendas, en inmueble único, para la satisfacción de las necesidades residenciales de sus asociados, en régimen de cesión de uso, podrá realizarse por las asociaciones privadas sin ánimo de lucro que se constituyan para tal finalidad.

2. En tal caso, el conjunto inmobiliario será propiedad de una asociación de las referidas, en pleno dominio u otro derecho que habilite para construir sobre él, y sus asociados, que serán personas fisicas, gozarán de un derecho de uso sobre la vivienda y locales que les sean adjudicados por la mencionada entidad conforme a las reglas que se prevean en sus estatutos y normas de organización interna.

3. Para acceder como socio a la asociación, en régimen de cesión de uso, habrá de abonarse un importe económico que será fijado por los órganos de gobierno de aquella en función de los costes de la promoción y mantenimiento del inmueble. Este importe de entrada se reembolsará en el caso de que quien lo hubiera abonado enajenare su derecho de uso a otra persona fisica bajo la fiscalización de los órganos de gobierno de la asociación, que habrán de garantizar la inexistencia de lucro o beneficio especulativo en la mencionada enajenación.

4. El derecho de uso del que gozará cada uno de los asociados tendrá carácter indefinido y será también transmisible «mortis causa" en sus propios términos y contenidos, y, en contraprestación a él, se abonará un canon o renta social establecido por la asociación de acuerdo con los costes de promoción, construcción, amortización, mantenimiento, mejoras y conceptos asimilables correspondientes al inmueble residencial.

5. Las asociaciones en régimen de cesión de uso que se acojan a lo previsto en la presente disposición y normativa que la desarrolle podrán ser destinatarias de las ayudas públicas que se les concedan al efecto, y el conjunto inmobiliario propiedad de la entidad se mantendrá permanente e indefinidamente en la titularidad de la asociación, no pudiendo tampoco transformarse en propiedad horizontal o cualesquiera otros regimenes privados de propiedad.

38 Sobre el Plan Director de Vivienda vid, http://www.etxebide.euskadi.eus/x39-ovad01/ es/contenidos/informacion/ovv_pdv_2018_2020/es_def/index.shtml 
ción de cooperativas en cesión de uso, apostando con ello decididamente por estos nuevos modelos de desarrollo para satisfacer las necesidades residenciales.

\section{Las tendencias de reforma de la Ley de Cooperativas}

El Proyecto de Ley de modificación de la actualmente en vigor LCE establece en su Exposición de Motivos que mantiene la estructura básica de diseño legislativo del cooperativismo de vivienda regulado actualmente y compartido con el resto de la legislación autonómica y estatal respecto de este tipo de cooperativas, sin embargo con las modificaciones propuestas pretende asegurar que las decisiones básicas de la construcción y gestión se realicen por los propios cooperativistas, democráticamente, desde su constitución; independientemente de que por la profesionalidad que requiere la promoción inmobiliaria y dada la forma de unirse las personas socias $^{39}$ de la cooperativa (personas socias que se desconocen entre sí habitualmente), sea necesaria la contratación de una entidad gestora que asesore sobre la construcción y financiación de la cooperativa. De esta forma, el texto apuesta decididamente por el aseguramiento de la información y transparencia de todas las operaciones, delegadas o no, de gestión ${ }^{40}$.

Asimismo, se permiten las operaciones con terceros, hasta un límite, respecto de las viviendas, en coherencia con la regulación existente para las otras clases de cooperativas reguladas por la LCE. El alcance de dichas operaciones llegaba a un cuarenta por ciento en el Proyecto de Ley aprobado si bien ha sido reducido a un treinta por ciento en el nuevo Anteproyecto de Ley. En cualquier caso, el acuerdo requerirá la homologación del Consejo Superior de Cooperativas de Euskadi, garantizándose de esta forma que dichas operaciones con terceros se justifican para el buen fin de la promoción y desterrándose al mismo tiempo cualquier atisbo especulativo que pudiera plantearse en este sentido ${ }^{41}$.

Como novedad muy importante se nos presenta que las cooperativas sólo podrán realizar una promoción, imposibilitándose la diversificación de éstas dentro de la misma sociedad al objeto sobre todo de aclarar la distribución de la responsabilidad de los socios que tantos problemas han

39 Es destacable el lenguaje no sexista que implementa el texto.

40 Proyecto de Ley aprobado por el Gobierno Vasco el 24 de mayo de 2016.

${ }^{41}$ En la actualidad se está trabajando sobre un Anteproyecto de Ley que introduce notables cambios respecto al Proyecto de Ley aprobado en el 2016, texto que hemos podido estudiar y al que se refieren nuestros comentarios conjuntamente con los realizados en relación al citado Proyecto aprobado. 
dado en el pasado. Adjudicada la propiedad de viviendas y locales promovidos, la cooperativa deberá liquidarse, pero siempre y cuando haya transcurrido el plazo de garantía y el legal previsto para responder de los vicios ocultos como entidad promotora a contar desde la fecha de su adjudicación, salvo que los estatutos o convenios de colaboración suscritos con entidades públicas establezcan un plazo superior. Por lo tanto, como vemos, se configura un modelo de una cooperativa/una promoción y su ulterior liquidación obligatoria una vez trascurrido los plazos de garantías necesarios.

Como continuidad del camino ya emprendido por la Ley de Vivienda de 2015, se establece que cuando la cooperativa promueva o adquiera un conjunto de viviendas y locales, todo ello como inmueble único, para su cesión a las personas socias, el conjunto inmobiliario será propiedad de la cooperativa en pleno dominio u otro derecho, con carácter indefinido o de duración determinada si así se prevé en los estatutos. En tal caso, las personas socias cooperadoras ostentarán un derecho de uso sobre la vivienda y locales que le sean adjudicados por la cooperativa conforme a sus estatutos y normas de organización interna que regularán sus derechos y obligaciones.

En este tipo de cooperativas de cesión de uso, para adquirir la condición de persona socia habrá de suscribirse una aportación al capital siendo su importe máximo el que le corresponda en función de los costes de promoción o adquisición del inmueble. Las personas socias abonarán además las cuotas periódicas que fijen los órganos de la cooperativa para el mantenimiento, mejora y conceptos asimilables correspondientes al inmueble residencial.

Sabido que unas de las cuestiones más delicadas en esta clase de cooperativas es la baja de las personas socias, se regula que su derecho de uso se pondrá a disposición del consejo rector que lo adjudicará a una nueva persona socia. De esta forma, es la cooperativa la que intermedia en la transmisión evitándose operaciones especulativas en el mercado. El derecho de uso es transmisible mortis causa a los causahabientes de la persona socia fallecida previa su admisión en la cooperativa, de conformidad con los requisitos generales, si así lo soliciten en el plazo de tres meses. En otro caso, tendrán derecho a la liquidación del crédito correspondiente.

El régimen de las personas socias ha sido uno de los más debatidos puesto que ante una primera aproximación en el sentido de regular que las cooperativas se constituirán por al menos, el cincuenta por ciento del total de éstas, se ha ido acotando en las diferente nuevas versiones de la reforma en el sentido de primero señalar que podrán computarse las personas socias colaboradoras sin perjuicio de la posterior incorporación de los adjudicatarios o cesionarios de las viviendas, de conformidad con las normas vigentes 
en materia de promoción de viviendas de protección pública ${ }^{42}$; y además clarificar en qué supuestos no será exigible tal porcentaje ${ }^{43}$.

La reforma ha venido a aclarar la duda existente hasta la fecha sobre la aplicación o no de la obligación contemplada en la Ley de 5 de noviembre de 1999 de Ordenación de la Edificación, estableciendo el carácter necesario del aval o seguro que garantice las cantidades anticipadas a cuenta de edificación a los adjudicatarios.

Si por algo se ha caracterizado la conflictividad en esta clase de cooperativas ha sido por las consecuencias económicas de la baja de los socios ${ }^{44}$, las cuales en muchas ocasiones han puesto en peligro el proyecto promocional en su totalidad. En efecto, a las dudas sobre el efecto del artículo 26.4 in fine de la LCE se le unía toda una serie de dudas interpretativas sobre la eficacia de los contratos de adquisición de la vivienda, lo cual ha hecho que la reforma contemple que la persona socia que cause baja de la cooperativa antes de la adjudicación de su vivienda o local, deberá seguir haciendo frente a los compromisos asumidos para su edificación, con el límite máximo que resulte del precio final para su adjudicación, todo ello hasta que no sea sustituido en sus derechos y obligaciones por otra persona socia o, en su caso, un tercero que no lo sea, en la vivienda o local que tuviese adjudicado, y manteniendo sus obligaciones cuando a esa nuevo adquiriente se le asignase otra vivienda o local diferente al suyo.

Con esto se define una responsabilidad de las personas socias de las cooperativas de viviendas como de carácter mancomunada simple, siendo su límite máximo el que se corresponda con el importe de sus aportaciones obligatorias y voluntarias al capital social, así como las cantidades entregadas a cuenta para hacer frente a la edificación y las que tuviese que realizar para cubrir el precio de adjudicación de su vivienda o local, salvo que tuviese un precio máximo fijado por la Administración, en cuyo caso ese será su límite de responsabilidad a todos los efectos ante la cooperativa, sus personas socias y terceros.

42 Busca la reforma no imposibilitar actuaciones promocionales de terceros no socios sobre todo a instancias de los poderes públicos y merced a convenios de colaboración. En caso contrario, y de no concretarse dicha excepción, es más que evidente que se dificultaría de forma notable el cooperativismo para la promoción de $\mathrm{d}$ vivienda protegida.

${ }^{43}$ Los supuestos que se excepcionan en el nuevo texto son:

a) Realizar una promoción concertada impulsada por la CAPV.

b) Realizar una promoción convenida con una o varias Administraciones, o entidades con participación pública.

c) Adquirir terrenos de dichas Administraciones o entidades con participación pública, bien por enajenación directa o por concurso.

44 En este sentido, vid. nota 23 de remisión al arbitraje cooperativo. 
Se mantiene la obligatoriedad de la auditoría de cuentas y se introduce, como especial y significativa novedad, la del letrado asesor de carácter necesario que asegura el referido objetivo de participación efectiva y gestión democrática al precisar de su dictamen respecto de las operaciones jurídico-económicas fundamentales.

Así, el letrado asesor dictaminará sobre la sujeción a derecho de los acuerdos que hagan referencia al objeto social y las operaciones que se realicen por terceros no personas socias, el régimen de adjudicación o cesión de las viviendas y locales, así como el de las personas socias; y más en concreto los siguientes:

a) De admisión de personas socias o de adhesión.

b) De sustitución de ex socios por nuevas personas socias o por personas no socias.

c) Contratos con la sociedad gestora.

d) Contratos de edificación.

e) Los que se fijen en los Estatutos de las Cooperativas.

Por último, esperemos que la reforma solucione la contradicción existente entre el artículo 138.7 de la LCE y el 18.1b) de la Ley de Vivienda en la medida que puedan las cooperativas adquirir terrenos de titularidad pública por el sistema de adjudicación directa sin ser necesaria la declaración de utilidad pública, que no sea de aplicación para las promociones de vivienda protegida, o en última instancia que se posibilite una declaración a través de un procedimiento extraordinario y urgente para estos supuestos.

\section{Conclusiones}

El reto del cooperativismo de vivienda es conectar cada vez más con las necesidades de un amplísimo sector de los demandantes de vivienda, compitiendo en el mercado con otro tipo de promociones inmobiliarias en lo verdaderamente importante: proveer viviendas de calidad, a precios asequibles y con total seguridad para los ciudadanos.

Así mismo, y a raíz de algunos de los últimos acontecimientos brevemente expuestos a lo largo del presente informe, debe saber comunicar a los medios de comunicación, a las distintas Administraciones Públicas, y a la sociedad en general, la actuación pasada y presente, así como las perspectivas de futuro del cooperativismo de vivienda en el País Vasco, todo ello en su condición de instrumento útil para lograr el acceso a una vivienda a todas las personas y familias que lo necesiten, en las mejores condiciones posibles de calidad y precio. 
El cooperativismo de vivienda tiene una larga experiencia de profesionalidad y calidad de los hogares entregados a sus socios, y es uno de los instrumentos más adecuado para dar la respuesta necesaria a la demanda no satisfecha por el mercado. La Sociedad tiene que conocer la importancia que el cooperativismo de Vivienda tiene, como parte de la economía social, tanto por las cuestiones cuantitativas, como por el papel social y articulador que aporta al sector inmobiliario y a la sociedad en general.

En este sentido, nadie puede hoy negar la importancia que hasta la fecha ha tenido este cooperativismo, especialmente en lo que hace referencia a la vivienda protegida, y de cómo ha sido un colaborador esencial de las distintas Administraciones en el desarrollo de políticas de vivienda en diferentes momentos históricos.

La aportación del cooperativismo al cumplimiento del mandato constitucional de facilitar a los ciudadanos una vivienda de calidad a un precio justo es indudable, y su importancia radica principalmente en estos elementos consustanciales al mismo, que es preciso recordar, a los efectos conclusivos:

1. El carácter de autopromoción elimina el beneficio del promotor, lo que abarata el coste final del producto, permitiendo entre otras cosas el acceso a una vivienda digna a un precio justo a sectores sociales que de otra forma estarían excluidos del mercado. Por ello, el modelo cooperativo constituye una oferta racional y eficiente para satisfacer la necesidad de vivienda, con una adecuación natural entre demanda y oferta, al estar asegurada la adjudicación de las viviendas entre sus socios.

2. ${ }^{\circ}$ La cooperativa es una figura de contenido social, democrático y participativo, al ser los propios socios destinatarios finales de las viviendas los que, a través de los órganos sociales legalmente establecidos, toman las decisiones sobre la promoción y controlan el desarrollo de la misma y participan en todo el proceso. Se rompe de esta forma la unilateralidad y adhesión que existe en otras fórmulas de promoción.

3. ${ }^{\circ}$ Las empresas gestoras de cooperativas de vivienda aportan, o al menos ese debe ser el único objetivo, profesionalidad, innovación, calidad, solvencia y garantía a las cooperativas y a los cooperativistas.

4. ${ }^{\circ}$ La responsabilidad social de las cooperativas es un valor principal, porque se evalúa y se considera de forma permanente el impacto de su actuación en todos los aspectos sociales, incluyendo los ámbitos urbanísticos y ecológicos, actuando para salvaguardar el adecuado equilibrio con el bien común. En este sentido, el cooperativismo ya ha demostrado que es capaz de hacer ciudad, cultura, barrio, 
con participación ciudadana, buscando la integración social en los desarrollos urbanísticos y favoreciendo el acceso a una vivienda a sectores amplios de la población.

5. ${ }^{\circ}$ Los nuevos modelos que están llegando, y muy especialmente las cooperativas de viviendas en cesión de uso, no hacen más que abrir nuevas posibilidades a los ciudadanos y, sobre todo, servir de útil instrumentos para vertebrar una nueva política pública de acceso a la vivienda por parte de la Administración.

6. ${ }^{\circ}$ En este trascendental momento histórico, la reforma de la LCE en los términos planteados va a servir sin duda de decidido impulso del cooperativismo de vivienda y de útil instrumento para concretar el derecho subjetivo a la vivienda elevado a rango de Ley en la CAPV desde el 2015.

\section{Bibliografía sobre cooperativas de viviendas}

AA.VV. (Fajardo, G., coord.), Las cooperativas de viviendas en la Comunidad Valenciana, constitución y funcionamiento, Ciriec-España, Valencia, 2014.

AA.VV., Perfiles tributarios del uso de la vivienda en la economía social y colaborativa (monográfico), Revista Jurídica de Economía Social y Cooperativa, n. ${ }^{\circ}$ 31, Ciriec-España, Valencia, 2017.

AA.VV. (Salinas, F. y Sanz, coords.), Las cooperativas de viviendas en España: desafios de presente y futuro, Publicaciones Universidad Católica de Ávila, Ávila 2003.

ELENA, F., Las tendencias actuales del cooperativismo de viviendas, Jornadas de estudio sobre cooperativismo, Dirección General de Cooperativas y Empresas Comunitarias, Ministerio de Trabajo, Madrid 1978.

Etxezarreta, A. et al., Social innovation and social economy: a new framework in the Spanish housing context, paper presented at ENHR conference in Lisbon, 2015.

Etxezarreta, A., Cano, G y Merino, S., Las cooperativas de viviendas de cesión de uso: experiencias emergentes en España, Revista de Economía Pública, Social y Cooperativa, n.o 92, Ciriec-España, Valencia, 2018.

Etxezarreta, A. y Merino, S., Las cooperativas de vivienda como alternativa al problema de la vivienda en la actual crisis económica, Revista de Estudios Cooperativos, n. ${ }^{\circ}$ 113, Madrid, 2013.

Fajardo, G, La responsabilidad del socio en la gestión de la cooperativa de viviendas desde la jurisprudencia del Tribunal Supremo, Revista de Legislación y Jurisprudencia de Ciriec-Espańa, n. ${ }^{\circ}$ 5, Valencia, 1994.

Fernández, I, Responsabilidad del socio frente a las deudas sociales originadas como consecuencia de la actividad promocional en las sociedades cooperativas de viviendas, Viviendas Cooperativas, n. ${ }^{\circ}$ 51, Madrid, 2000. 
González, R., Las cooperativas de vivienda de responsabilidad limitada no existen, Revista de Estudios Cooperativos, n. ${ }^{\circ}$ 67, Madrid, 1999.

Gómez, A.P., Análisis de los aspectos financieros de la Sociedad Cooperativa de Viviendas en España, Madrid, 1991.

Lambea, A. Adjudicación y cesión de uso en las Cooperativas de Viviendas: usufructo, uso y habitación y arrendamiento, Revista Jurídica de Economía Social y Cooperativa, n. ${ }^{\circ} 23$, Valencia, 2012.

Lambea, A., Código de conducta en el sector de cooperativas de viviendas. Normas de buenas prácticas empresariales de las empresas gestoras de cooperativas (GECOPI), Revista de Estudios Cooperativos, n. ${ }^{\circ}$ 108, Madrid, 2012.

Lambea, A., Cooperativas de viviendas (3. ${ }^{\mathrm{a}}$ edición), Comares, Granada, 2012.

Lambea, A., Rehabilitación, regeneración y renovación urbana. Experiencias novedosas en cooperativas de viviendas: rehabilitación y mediación, Revista Jurídica de Economía Social y Cooperativa, n. ${ }^{\circ}$ 26, Ciriec-Espańa, Valencia, 2015.

Merino, S., Cooperativas de viviendas, Manual de Derecho de Sociedades Cooperativas, Consejo Superior de Cooperativas de Euskadi, Vitoria-Gasteiz, 2008.

Merino, S., Cooperativas de Viviendas, Tratado de Derecho de Cooperativas (Dtr. Juan Ignacio Peinado), Tomo II, Tirant lo Blanc, Valencia, 2013.

Merino, S., La cooperativa de viviendas como administradora de bienes comunes, Revista Vasca de Economía Social, n. ${ }^{\circ}$ 9, Bilbao, 2013.

Oñate, J., Comentarios a la Ley de Cooperativas. Transmisión intervivos de la vivienda entregada, Viviendas Cooperativas, n. ${ }^{\circ}$ 53, Madrid, 2000.

Vázquez, A. y Fraile, A. Las cooperativas de viviendas y el Proyecto de Ley de Cooperativas, Revista de Estudios Cooperativos, n. ${ }^{\circ}$ 66, Madrid, 1998. 